\title{
Noni a Wonder Plant (Therapeutic Properties): A Review
}

\author{
P.S. Mahantesh *, J.S. Hiremath., C.H. Lokesh, Y. Ravi., \\ M.D. Sameer Hussain and M.R. Pooja \\ Department of Plantation, Spices, Medicinal and Aromatic crops, KRC College of \\ Horticulture, Arabhavi, University of Horticultural Sciences, Bagalkot, \\ Karnataka-591 218, India \\ *Corresponding author
}

A B S T R A C T

\begin{tabular}{|l|}
\hline Ke y w or d s \\
Morinda citrifolia, \\
Rubiaceae, \\
Therapeutic \\
properties
\end{tabular}

Morinda citrifolia Linn. belongs to family Rubiaceae, also called as 'noni' is an evergreen shrub that originated in Southeast Asia and is being used from many centuries as traditional medicine. Various communities throughout the world consume the fruit and leaves of this traditional medicinal plant for its various therapeutic properties. M. citrifolia parts including fruits, seeds, barks, leaves, and flowers are utilized on their own for individual nutritional and therapeutical values, however, the fruit is considered to contain the most valuable chemical compounds. Morinda citrifolia is found to have a broad range of therapeutic effects like antiviral, antibacterial, antifungal, antitumor, antihelmintics, analgesic, hypotensive, anti-inflammatory, immune enhancing effect. Hence, the juice obtained from ripe and unripe fruit seems to be a more recent innovation that has been commercially exploited to a greater extent in recent times. The present review is focused on medicinal values of Morinda citrifolia which is very helpful in fighting different health ailments.

\section{Introduction}

Morinda citrifolia Linn (Rubiaceae) commonly known as Noni, is a traditional and Polynesian medicinal plant that has been used for more than 2000 years. When the ancestors of Polynesians migrated from South East Asia they brought many plants with them for food and medicinal purposes, among them Noni was one of the most popular herbal medicinal plant that was used to treat many types of diseases (Adams). In the early 1990s, the first commercialized products derived from $M$. citrifolia fruit in USA were lunched (Santhosh). Later, in 1996, M. citrifolia juice was introduced as a wellness drink, due to numerous reports stating its therapeutic effects (Kamiya). In 2003, the fruit juice of $M$. citrifolia was approved as a novel food by the European commission; however, this approval was limited to the Tahitian fruit juice and not to other products (Potterat).

\section{Medicinal properties}

\section{Analgesic activity}

Younos et al., (1990) reported the analgesic and sedative effects of extracts from the Morinda citrifolia plant. The extract showed a 
significant, dose-related, central analgesic activity in the treated mice." They stated that "these findings validate the traditional analgesic properties of this plant." The analgesic efficacy of the Noni extract is $75 \%$ as strong as morphine, yet non addictive and side effect free. Noni was tested for its analgesic properties by the "twisted method" animal model.

\section{Hypotensive activity}

Moorthy and Reddy found that an ethanol extract of the Noni roots lowered the blood pressure in an anesthetized dog. They also determined that hot water extract of Noni roots lowered the blood pressure of an anesthetized dog. A Hawaiian physician reported that Noni fruit juice had a diuretic effect.

\section{Immunological activity}

Asahina found that an alcohol extract of Noni fruit at various concentrations inhibited the production of tumor necrosis factor-alpha (TNF-a), which is an endogenous tumor promoters. Therefore the alcohol extract may inhibit the tumor promoting effect of TNF-a. Hirazumi found that noni contains a polysaccharide rich substance that inhibited tumor growth. It did not exert significant cytotoxic effects in adapted cultures of lung cancer cells, but could activate peritoneal exudates cells to impart profound toxicity when co-cultured with the tumor cells.

\section{Anti-inflammatory activity}

Horton et al., reported that interest in cancer chemoprevention with COX-2 inhibitors has been stimulated by epidemiological observations that the use of aspirin and other non-steroidal inflammatory drugs (NSAIDs) is associated with the reduced incidence of colon and breast cancer. The main target of NSAID activity is the cyclooxygenase (COX) enzyme. Two isoforms of COX have been identified: COX-1, the constitutive isoform, and COX-2, the inducible form of the enzyme. COX-2 can undergo rapid induction in response to chemical carcinogens. It has been suggested that COX-2 over expression may lead to increased angiogenesis and inflammatory reaction.

Therefore the inhibition of COX-2 might have a general cancer preventive effect via antiinflammatory activity and decrease angiogenesis. In this study, the selectivity of COX-2 inhibition of Noni versus COX-1 in vitro was investigated. The discovery of the selective COX-2 inhibition of Noni is very significant since Noni is a natural fruit juice without side effects. This is the first scientific evidence for a strong anti-inflammatory activity in Noni, which may also be one mechanism of cancer prevention.

\section{Cancer preventive effect of Morinda citrifolia (Noni)}

Liu et al., ${ }^{9}$ the hypothesis that Morinda citrifolia, L possesses a cancer preventive effect at the initiation stage of carcinogenesis was studied. One preliminary data indicated that $10 \%$ Noni Juice made from Morinda citrifolia fruit in drinking water for one week was able to prevent DMBA-DNA adduct formation.

The levels of DMBA-DNA adducts were reduced by $30 \%$ in the heart, $41 \%$ in the lung, $42 \%$ in the liver, and $80 \%$ in the kidney of female SD rats. Even more dramatic results were obtained in male C57 BL-6 mice: 10\% noni was able to reduce DMBA-DNA adduct formation by $60 \%$ in the heart, $50 \%$ in the lung, $70 \%$ in the liver, and $90 \%$ in the kidney. In order to explore the mechanism of this preventive effect, the antioxidant activity of Noni was examined in vitro by lipid hydro 
peroxide (LPO) and Tetrazolium nitroblue (TNB) assays. The results suggest that prevention of carcinogen-DNA adduct formation and the antioxidant activity of noni may contribute to the cancer preventive effect of Morinda citrifolia.

\section{Noni against diabetes}

Sathish reported that, both genetic and environmental factors are implicated in the causation of Type 2 diabetes. Among environmental factors; over eating decreased physical activity and obesity, cigarette smoking, increased oxidant stress, and inflammatory processes have been associated, either as a cause, or an effect of the developing diabetic state.

Patients diagnosed with Type 2 diabetes milletus for at least 5 years, who are currently on insulin and not adequately controlled with current treatment, with $\mathrm{HbA} 1 \mathrm{c}>8 \%$. Present study highlights how patients inadequately controlled with an existing insulin treatment and Oral Hypoglasmic agents (OHS). By adding Noni as a food supplement significant improvement in $\mathrm{HbA} 1 \mathrm{c}$ and FBG is observed after 6 months follow-up.

Shivananda et al., reported that the fermented fruit juice of the M. Citrifolia (optical density $=1.25$ ) was used to study the hypoglycemic and hepatoprotective properties in diabetesinduced rats. The rats were randomly distributed into 4 groups (control, diabetic experimental, diabetic standard, and diabetic untreated) of 6 each. Diabetes was induced by administering Streptozotocin $(50 \mathrm{mg} / \mathrm{kg}$ body weight). Fasting blood glucose, body mass, liver tissue glycogen content, and the extent of liver degeneration were assessed. Diabetic experimental animals were treated with $M$. citrifolia juice ( $2 \mathrm{ml} / \mathrm{kg}$, twice a day) and diabetic standard with reference hypoglycemic drug, glibenclamide orally for 20 days. Both the groups exhibited a significant reduction in blood glucose level of $150 \mathrm{mg} / \mathrm{dl} \pm 15.88$ and $125 \mathrm{mg} / \mathrm{dl} \pm 3.89$, respectively, as compared to diabetic untreated with FBS $=360.0 \mathrm{mg} / \mathrm{dl}$ $\pm 15.81,(P<.003)$. On 10th day of experiment, diabetic experimental animals exhibited a decrease in body mass $(10.2 \mathrm{~g}, 5.11 \%)$ which increased significantly by the 20th day $(6 \mathrm{~g}$, $3.0 \%, P<.022)$. Histological study of liver tissue obtained from untreated diabetic animals revealed significant fatty degeneration as compared to other three groups. The data of this study proved the hypoglycemic and hepatoprotective activity of $M$. citrifolia.

\section{Anti-HIV Activity and cytotoxicity of Noni}

Selvam et al., reported that fruit juice and ethanol, methanolic extract of fruit powder of Morinda citrifolia (MC) have been studied against the replication of HIV-1(IIIB) in MT-4 cells. Fruit juice of Morinda citrifolia (MC) exhibited a maximum protection of $18 \%$ of the cells against the cytopathic effect of HIV1(IIIB) strain and displayed marked cytotoxic activity in lymphocyte (MT-4) cells (CC50: $0.19 \mathrm{mg} / \mathrm{ml})$. However the ethanol (EMC) and methanol extracts (MMC) displayed cytotoxic activity (CC50) in lymphocyte (MT-4) cells only at higher concentration the CC50 being at 72.34 and $220 \mu \mathrm{g} / \mathrm{ml}$, respectively.

Paul et al., reported that the MCF-Ac, MCFEt, MCF-Me extracts showed cytotoxicity against HepG2 cells with CTC50 values of $200 \mu \mathrm{g} / \mathrm{ml}, 220 \mu \mathrm{g} / \mathrm{ml}$ and $246 \mu \mathrm{g} / \mathrm{ml}$. MCFAc and MCF-Me extracts treated with different concentrations and showed a dose dependent increase in Hepatoprotection percentage ranged between $72-84 \%$ at $100-$ $150 \mu \mathrm{g} / \mathrm{ml}$. MCF-Ac, MCF-Et and isolated compounds from MCF-Me extracts (C-9, MeI, II and III) were tested against anti-HIV, MCF-Ac extract exhibited anti-HIV-1 and 2 replication in MT-4 cells with maximum protection $2-76 \%$ IC50 values of 157.0 and $37.04 \mu \mathrm{g} / \mathrm{ml}$, respectively. 


\section{Plant and its parts}
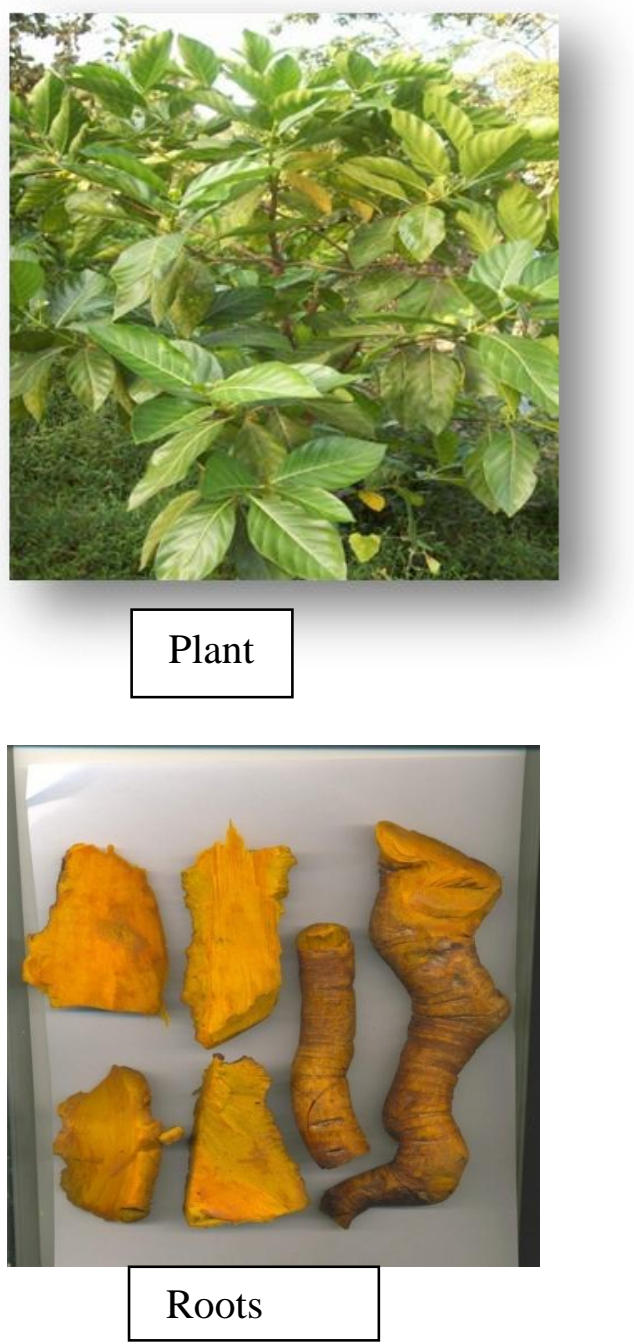

\section{Noni against breast cancer}

Rangadhar reported that, the mainstay of breast cancer treatment is surgery when the tumor is localized, with possible adjuvant chemotherapy, and /or radiotherapy. Depending on clinical criteria (age, type of cancer, size, metastasis) patients are roughly divided in to high risk and low risk cases, with each risk category following different rules for therapy. Treatment possibilities include radiation therapy, chemotherapy, hormone therapy, and immune therapy. Nothing guarantees that you won't develop breast cancer. There are lots of side effects of
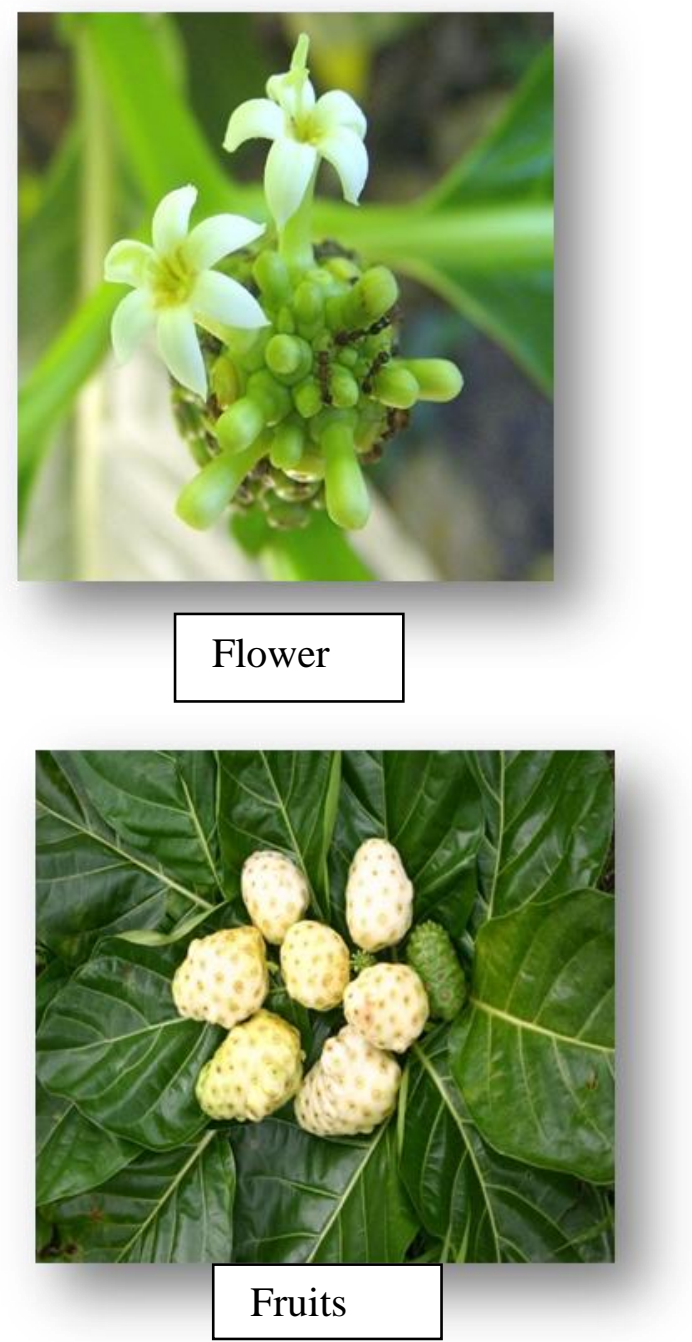

chemotherapy and radiotherapy that makes the patient worse than cancer itself. Indian Noni helps to overcome maximum side effects of all cancer cases including the breast cancer by its immune enhancing and nutritive supplementing property. It also contains many bio anti carcinogenic ingredients that helps by enhancing the efficacy of the cancer treatment too. It acts as a tool for primary prevention, secondary prevention and as an adjuvant immune enhancing supplement with the common line of cancer treatment.

Johnson et al., reported the cytotoxic effects of water and ethanol extracts of whole noni 
fruit, pulp, peel and seed are studied on HMEC (Clone tics Human Mammary Epithelial Cells), MCF-7 breast carcinoma and an invasive variant of MCF-7(MCF-7i), which was developed in our lab. The XTT protocol from Boehringer Mannheim and the ToxiLight and ViaLight HS protocols from Bio Whittaker were used to determine the cytotoxicity of noni extracts on all three cell lines. Initial data indicate that noni demonstrates general cytotoxicity and this effect was similar on normal breast epithelial HMEC cells, non-invasive and invasive breast carcinoma cells MCF-7 and MCF-7i.

\section{Noni against Psoriasis}

Hiroshi revealed that, a 31-year-old man with a 14-year history of psoriasis developed polyarthritis in 2008 and was admitted to a clinic. Weekly monotherapy with $8 \mathrm{mg}$ of methotrexate (MTX) did not ameliorate his arthritis and treatment with etanercept $(25 \mathrm{mg}$ every other week) was started in addition to the MTX. Although his economical situation prevented him from using a full dose of etanercept, his arthritis significantly ameliorated and his DAS28-CRP decreased to 1.52. Despite the remission of arthritis, his psoriatic skin lesions were not improved (Fig. 1, upper panel). He then took $4 \mathrm{~g} /$ day of Morinda citrifolia (Noni) powder together with weekly MTX and ceased taking etanercept injections. Although his arthritis worsened after one month, (DAS28-CRP was 2.79), his psoriatic skin lesions surprisingly improved significantly.

\section{Noni as wound healer and antioxidant}

Smith reported the wound healing properties of the chloroform extract of Morinda pubescens fruit in rats. Topical application of M. pubescens fruit extract at $20 \mathrm{mg} / \mathrm{ml}$ and 10 $\mathrm{mg} / \mathrm{mL} \quad$ concentrations appreciably accelerated wound healing in rats compared with controls. Complete wound contraction was achieved, and fresh hair began to grow in the entire wounded area within 15 days in animals treated with the $20 \mathrm{mg} / \mathrm{ml}$ chloroform fruit extract of $M$. pubescens compared with only $60 \%$ contraction without hair growth in control rats.

Vijaykumar et al., evaluated the effect of aqueous extract of leaves of Morinda citrifolia $(200 \mathrm{mg} / \mathrm{kg})$ on excision, resutured incision and dead space wound models were studied. Changes in blood malondialdehyde (MDA) levels and histopathological studies were also carried out. There was a significant increase $(p<0.0001)$ in wound contraction rate, tensile strength, granuloma breaking strength, collagen content, dry granuloma weight $(p<0.01)$ and hydroxyproline content. A significant decrease $(p<0.0001)$ in epithelialisation period and MDA levels in Morinda citrifolia leaf extract treated group were observed when compared to control group. From the results, it may be concluded that the $M$. citrifolia aqueous leaves enhances the wound healing and possess antioxidant activity.

\section{Antibacterial and antifungal activity of Noni}

Sathish et al., reported that the ethyl acetate extract was effective against most of the microorganisms tested except Pseudomonas aeruginosa and Klebsiella pneumoniae. Hexane extract was ineffective against all tested microorganisms. Among the fungi tested, the maximum percentage of inhibition was observed against Trichophyton mentagrophytes with the extracts of methanol $(79.3 \%)$ and ethyl acetate $(62.06 \%)$. Nearly $50 \%$ inhibition was recorded against Penicillium sp., Fusarium sp. and Rhizopus sp. with methanol extract. None of the extracts were active against Candida albicans and Aspergillus species. The methanol extract 
showed maximum cytotoxicity on HEp2 cells followed by ethyl acetate extract. The overall results indicate promising baseline information for the potential uses of $M$. citrifolia fruit extracts in the treatment of infectious diseases and tumor.

Jai et al., reported the antibacterial activity of Morinda citrifolia leaf, fruit and seed extract was assessed in-vitro by using disc diffusion method. A total of five different accessions of $M$. citrifolia plants were randomly selected and screened for antibacterial activity against five different bacterial pathogens. Overall analysis of the antibacterial activity of various extracts revealed that the best inhibitory activity was produced by the seed extract $(12.23 \mathrm{~mm})$ compared to the leaf and fruit extract. E. coli and the Pseudomonas spp were inhibited by all the extracts; however, Salmonella spp., Staphylococcus aureus and Klebsiella spp were not inhibited by all the extracts.

\section{Antidyslipidemic effects of Noni}

Rehaman et al., reported that the aqueous ethanolic extract reduced the total cholesterol and triglyceride levels in triton-induced dyslipidemia. In high fat diet-induced dyslipidemia all these extracts caused significant reduction in total cholesterol, triglyceride, low density lipoproteincholesterol (LDL-C), atherogenic index and TC/HDL ratio. Mc.Cr.R extract also caused increase in high density lipoproteincholesterol (HDL-C). The Mc.Cr.L and Mc.Cr.R reduced gain in body weight with a reduction in daily diet consumption but Mc.Cr.F had no effect on body weight and daily diet consumption.

\section{References}

Adams, R. P., 2001. Identification of essential oil components by gas chromatography/ quadrupole mass spectroscopy. Carol Stream: Allured Publishing Co.

Asahina, A.Y., Ebesu, J. S. M., Ichinotsubo, D., Tongson, J. and Hokama, Y., 1992. Effect of okadaic acid (OA) and noni fruit extract in the synthesis of tumor necrosis factor $-\mathrm{a}$ (TNF-a) by peripheral Blood Mononuclear (PBM) cells in vitro. Department of Pathology, John A. Burns School of Medicine, University of Hawaii, Honolulu, HI.

Hirazumi, A., Furusawa, E., Chou, S. C. and Hokama, Y., 1996. Immunomodulation contributes to the anticancer activity of Morinda citrifolia (noni) fruit juice. Proc. West Pharmacol. Soc., 39: 7-9.

Hiroshi, O., Morinda citrifolia (Noni) in the treatment of Psoriasis. The Open General and Internal Medicine Journal, 5: 1-2 (2012).

Horton, J. K., Williams, A. S., Smith, P. Z., Martin, R. C. and Beirne, G., Effect of anti-inflammatory drugs on cyclooxygenase activity and prostanoid expression. Anal, Biochem., 271: 18-28 (1999).

Jai, S., Singh, D. R. Jeyakumar, S., Kundu, A. and Arun K., 2011. Antibacterial activity in solvent extract of different parts of Morinda citrifolia. Plant J. Pharm. Sci. and Res., 3(8): 1404-1407.

Johnson, A., Hemscheidt, S. T. and Csiszar, W. K., 2002. Cytotoxicity of water and ethanol extracts of Morinda citrifolia (L.) against normal epithelial and breast cancer cell lines. Proceedings, Hawaii Noni Conference, 22.

Kamiya, K., Hamabe, W., Tokuyama, S. and Satake, T., 2009. New anthraquinone glycosides from the roots of Morinda citrifolia. Fitoterapia, 80(3):196-199.

Liu, G., Bode, A., Ma, W. Y., Sang, S., Ho, C. T. and Dong, Z., 2001. Two novel glycosides from the fruits of Morinda citrifolia (noni) inhibit AP-1 transactivation and cell trans formation 
in the mouse epidermal JB6 cell line. Cancer, Res., 61: 5749-5756.

Moorthy, N. K. and Reddy, G. S., 1970. Preliminary phytochemical and pharmacological study of Morinda citrifolia, Linn. Antiseptic, 67: 167-171.

Paul, P. T., Selvam, P., Rama, M. and Guptha, V., 2015. Investigation of antiHIV, cytotoxicity and hepatoprotective activities of Morinda citrifolia (Noni). World J. Pharmaceutical Research. 4(1): 224-230.

Potterat, O. and Hamburger, M., 2007. Morinda citrifolia (noni) fruit phytochemistry, pharmacology, safety. Planta. Med., 73(3): 191-195.

Rangadhar, S., 2007. Effects of noni (Morinda citrifolia L.) on carcinoma of breast cancer cells. Noni Cli. Res. J., 1(1-2): 28-33.

Rehman, Mandukhail, N. A. and Anwarul, H. G., 2010. Lipids in health and Disease, 9: 88- 93 .

Santhosh, M., Rama Rao, N., Deepthi, B., Lakshmi, P. J. and Surya, P. M., 2013. A hurb of medicinal values. International Journal of Biological and Pharmaceutical Research 4(12): 10431049

Sathish, G., 2007. The effect of Noni (Morinda citrifolia L.) in Type 2 diabetes mellitus in inadequately controlled patients. Noni Cli. Res. J., 1(1-2): 20-24.
Sathish, K., Jayaraman, M., Saravanan, M., Seethalakshmi, I., 2008. Antibacterial, antifungal and tumor cell suppression potential of Morinda citrifolia fruit extracts. International J. Integrative Biology, 3(1): 44-49.

Selvam. P., Narayanan, S., Murugesh, M. and Witvrouw, 2007. Studies of Comparative Anti-HIV activity and cytotoxicity of Morinda citrifolia L. Noni Cli. Res. J., 1(1-2): 25- 27.

Shivananda, N. B., Julien, R. M., Godwin, I. and Andrew, A., 2011. Hypoglycemic and hepatoprotective activity of fermented fruit juice of Morinda citrifolia (Noni) in diabetic rats. Evidence-Based Complementary and Alternative Medicine, 5: 509-511.

Smith, J. E., 2006. Morinda pubescens (Morinda tinctoria Roxb.) Fruit extract accelerates wound healing in rats, J. Med. Food, 9(4): 591-593.

Vijay, K., Pandurang, R., Arulmozhi, S., Purnima, A. and Sridhar, Y., 2008 Wound healing and Antioxidant activities of Morinda citrifolia leaf extract in rats. Iranian J. Pharmacol. Ther., 7(1): 49-52.

Younos, C., Rolland, A., Fleurentin, J., Lanhers, M. C., Miss, R. and Mortier, F., 1990. Analgesic and behavioral effects of Morinda citrifolia. Planta. Med., 56: 430-436.

\section{How to cite this article:}

Mahantesh, P.S., J.S. Hiremath., C.H. Lokesh, Y. Ravi., M.D. Sameer Hussain and Pooja, M.R. 2018. Noni a Wonder Plant (Therapeutic Properties): A Review. Int.J.Curr.Microbiol.App.Sci. 7(02): 2722-2728. doi: https://doi.org/10.20546/ijcmas.2018.702.331 